\title{
Mapping wastes in complex projects for Lean Product Development
}

\author{
Valeria Belvedere ${ }^{\mathrm{a}, *}$, Francesco Cuttaia ${ }^{\mathrm{b}}$, Monica Rossi ${ }^{\mathrm{c}}$, Luca Stringhetti ${ }^{\mathrm{d}, \mathrm{e}}$

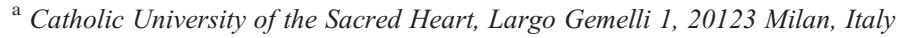 \\ ${ }^{\mathrm{b}}$ INAF - Osservatorio di Astrofisica e Scienza dello Spazio, via Gobetti 101, 40129 Bologna, Italy \\ ${ }^{c}$ Politecnico di Milano, via Lambruschini 4/b, 20156 Milan, Italy \\ d SKA (Square Kilometre Array) Organisation, Jodrell Bank, Cheshire, United Kingdom \\ e INAF - IASF Milano, Via Corti 12, 20133 Milan, Italy
}

\begin{abstract}
Lean Product Development (LPD) is suggested as an approach that can reduce waste in projects aimed at developing technically complex items, which typically present substantial uncertainty about their output, as well as higher costs and longer development times. However, how can LPD be implemented in complex projects, where some redundancies in the development process are considered necessary in order to guarantee the quality of the final outcome? This paper answers this question, through a survey conducted at INAF, the Italian Institute of Astrophysics, that runs complex projects. The evidence shows that complex projects can actually be affected by the types of waste reported in LPD literature. Still, researchers may fail to determine the real priorities of intervention as they have trouble distinguishing between value-adding and value-destroying activities. Furthermore, they do not perceive the relevance of addressing the wastes generated by their own work; on the contrary, they place considerable attention on inefficiencies that are beyond the scope of their direct responsibilities. Recommendations to overcome this problem are proposed.
\end{abstract} (C) 2019 Elsevier Ltd, APM and IPMA. All rights reserved.

Keywords: Lean product development; Complex projects; Project performance; Waste; Astrophysics; Survey

\section{Introduction}

Lean Product Development (LPD) is the application of lean thinking and principles to Product Development (PD) projects, in an attempt to support companies willing to implement lean thinking, tools and techniques to improve the overall performance of their processes (Rossi et al., 2017; Rossi et al., 2011; Oehmen and Rebentisch, 2010; Locher, 2008; Morgan and Liker, 2006). Even though lean thinking was conceived as an overall approach encompassing the whole enterprise (Womack

\footnotetext{
* Corresponding author.

E-mail addresses: valeria.belvedere@unicatt.it (V. Belvedere), francesco.cuttaia@inaf.it (F. Cuttaia), monica.rossi@polimi.it (M. Rossi), 1.stringhetti@skatelescope.org (L. Stringhetti).
}

et al., 1990), in the beginning it was applied mainly on production floors to improve the transformation processes of manufacturing companies (Womack and Jones, 1996), especially those carrying out repetitive operations and producing large volume products (e.g. the automotive industry). In this regard two points are to be noted.

First of all, PD is different from a repetitive production process, in that the main input and output of the former is information, while the latter mainly deals with materials (Morgan and Liker, 2006; Krishnan and Ulrich, 2001). Secondly, PD typically has a higher level of variability and uncertainty compared to the production processes of large scale manufacturing companies and this could prevent an effective delivery of value and identification of the "waste" (Browning and Sanders, 2012). The latter problem can be further 
exacerbated in organizations that manage complex projects, where the item to be developed presents a high level of technical complexity and can result in an even higher uncertainty about the output, as well as involve higher costs and longer development times (Lu et al., 2015; Metcalfe and Sastrowardoyo, 2013; Geraldi et al., 2011; Vidal et al., 2011; Williams, 1999; Baccarini, 1996).

Although extant contributions argue that a trade-off between effectiveness and efficiency exits, recent studies have challenged this idea, providing evidence about the existence of a positive correlation between the two performance categories in the context of complex projects (Serrador and Turner, 2015; Turner and Zolin, 2012). Thus, the academic discussion is now focused on the managerial practices and methods that can be employed in order to boost project's efficiency. Indeed, the possibility of improving the overall performance of complex development processes through the proper adoption of best practices and innovative methods has been recently highlighted as a must in several sectors, due to the need to achieve not only high performing outputs, but also adequate cost and time performance (Rossi and Terzi, 2017).

This is particularly evident in the aerospace sector, which is increasingly characterized by complex projects that require technical instruments, the development of which is spread over many years and is mostly based on in-progress technologies (Locatelli et al., 2014; Oehmen, 2012; Oppenheim et al., 2011; Billings, 2010). Although the deliverables of this industry are "one-of-a-kind" complex pieces of equipment with low repeatability, the development process should embed best engineering practices that are repeatable and that are mostly rooted in lean management principles (Oppenheim et al., 2011). The need for such practices has been highlighted by studies according to which the amount of value-adding activities in aerospace projects is in the range of 12\%-13\% (Oppenheim, 2004; Murman et al., 2002). According to Oppenheim (2004) this is due to the craft mentality of engineers, poor planning, ad hoc execution, and a poor coordination and communication culture, which could be reduced if lean principles were embedded into design processes. However, in these organizations, due to the complexity of the systems to be developed, some redundancies are considered normal and even necessary in order to reach the technical perfection of the equipment (Belvedere and Stringhetti, 2014).

This aspect can jeopardize the possibility of actually distinguishing between value-adding activities and inefficiencies, which is essential for identifying and removing wastes according to LPD literature (Rossi et al., 2017; Browning and Sanders, 2012).

This paper seeks to contribute to the discussion on the relationship between complex projects' efficiency and effectiveness and on the possibility to boost the former through the adoption of LPD. In particular, we want to contribute to this field of knowledge and practice by investigating on the types of wastes that employees experience in complex projects and understanding how the principles of LPD can be used to plan improvement actions in this kind of environment. This would clearly have strong practical implications for the management of complex projects as it would support the identification of the main types of waste and prioritize their impact so that highly effective improvement plans could be drawn up.

In order to address this research objective, after outlining reference literature on LPD, waste and complex projects, we describe the outcomes of the empirical investigation we carried out at INAF, the Italian Institute of Astrophysics, where we had the chance to establish initial findings on the types of waste that mainly affect complex projects and how to tackle them effectively.

\section{Literature review}

Following the introduction to the definition and origin of LPD, this section discusses the concept of waste in PD as well as state-of-the-art research on the application of such thinking on complex projects management.

\subsection{Towards lean product development}

The application of lean thinking and principles to Product Development (PD) is labelled as Lean Product Development (LPD). LPD is the practice of "creating value through a process that builds on knowledge and learning enabled by an integrated product development system, consisting of people, processes, and technology" (Rossi et al., 2017). In turn, PD is defined as the "transformation of a market opportunity and a set of assumptions about product technology into a product available for sale" (Krishnan and Ulrich, 2001).

Even though for years the focus on lean management implementation has been on manufacturing, research on LPD began simultaneously in the late 1980s with Clark et al. (1987), who discovered that Japanese automotive manufacturers outperformed their Western competitors in terms of engineering hours and time to market. According to these authors, this difference was due to the overlap of development activities, the strong involvement of suppliers, and cross-functional project management. Around the same period of time, Womack et al. (1990) mentioned the application of lean principles to PD and discussed lean design techniques, like project managers, simultaneous development, teamwork, and communication.

A few years later, Liker et al. (1996) discovered that socalled Set-Based Concurrent Engineering was the reason for Toyota's success. Toyota was able to develop products faster by developing parallel design alternatives and delaying the final choice to the very end of the process. Set-based concurrent engineering was later added to Ward and Sobek's LPD system (Ward and Sobek II, 2014), along with four other pillars: (i) Value Focus; (ii) Entrepreneur System Designers; (iii) Cadence, Flow and Pull; and (iv) Teams of Responsible Experts.

Companies that successfully implement lean manufacturing programs also generally launch LPD programs (Morgan and Liker, 2006; Sobek II et al., 1998), despite acknowledging the complexities related to their implementation (Karlsson and Ahlstrom, 1996). In fact, the application of lean principles to PD offers at least three important advantages to companies: 
1. It improves PD performance by reducing time to market and development costs (Liker and Morgan, 2011);

2. It further boosts the efficiency in lean manufacturing (Liker and Morgan, 2011);

3. It is a step forward towards the lean enterprise, which means exploiting the increased productivity deriving from coupling LPD with lean manufacturing (Womack and Jones, 1996).

Despite all the advantages mentioned above, effective ways to implement LPD are still controversial. For years, lean manufacturing applications preceded LPD applications and this had led many scholars and practitioners to naively consider LPD to be a mere reflection of lean production (Rossi et al., 2017). Therefore, some scholars simply suggest that many tools can be directly applied to PD without any relevant change or adaptation to the features of this process. For example, Reinertsen (2005) showed how queue management, batch size reduction, cadence, rapid local adjustments and waste eliminations can be applied to reduce bad variability in PD.

While not completely untrue, for years this belief limited the exploitation of the real power behind LPD, hindering the unveiling of its full potential. As LPD is rooted in the experience of the principles applied to the Toyota Production System, Toyota's PD process should be used as a reference benchmark, as many scholars are now proposing, extending LPD understanding beyond the mere reflections of lean manufacturing tools and to LPD applications (Ward and Sobek II, 2014). For example, Sobek II et al. (1999a, b) discovered that Toyota applies the concept of Set-Based Concurrent Engineering, which starts with the generation of multiple alternatives to the problem and then culminates with the choice of the most suitable alternative.

Toyota's LPD system has undoubtedly drawn considerable attention, thanks to its impressive results, in terms of time to market, engineering productivity and project success, to mention but a few (Kennedy, 2008; Morgan and Liker, 2006). Following these remarkable results, not only the automotive and more traditional sectors, but also other sectors, including the space industry, started to look at the concepts of concurrent engineering and lean engineering and management, starting with JPL in the Team-X example (Smith, 1998), followed by the ESA Concurrent Design Facility (Bandecchi et al., 2000).

Despite the level of product complexity and the nature of the industry, as well as the above mentioned differences on how lean thinking results in LPD vs. manufacturing applications, both literature and practice agree on the huge role played by waste elimination in the improvement of processes in any kind of environment. However, literature on LPD waste is not as detailed as literature on lean production, especially when it comes to complex projects and non-traditional sectors. An overview of the status of current PD waste understanding is given below.

\subsection{Waste in product development}

The concept of waste has not yet gained a general consensus in the literature on LPD, although the identification of the main types of waste and their elimination is unanimously considered the first step in the implementation of lean principles.

Morgan and Liker (2006) define waste as any activity that absorbs resources without adding value for the customer and they suggest applying the seven categories of waste identified by Ohno (1988) also to PD, despite the difficulties related to their translation into a different domain. In fact, the waste types proposed by Ohno (1998) were developed for the manufacturing environment, while the output of PD is generally a productrelated information. Based on Liker's classification (2004), Locher (2008) developed a list of eight types of waste in PD that is similar to the list proposed for manufacturing, but reinterpreted to fit the PD environment. According to such a classification, the different types of PD waste are as follows: overproduction, waiting, transportation, processing, inventory, defects (and correction), motion and underutilized people.

Oehmen and Rebentisch (2010) propose another taxonomy in PD. They summarize the categorizations of waste of nine different authors into the following eight: overproduction of information, over-processing of information, miscommunication of information, stockpiling of information, generating defective information, correcting information, waiting of people and unnecessary movement of people. Compared to Morgan and Liker (2006), this list is more focused on the information flow and appears useful for taking a specific feature of the PD into account, i.e. the relevance of information as the input and output of the stages in this process.

For a more comprehensive identification and deeper understanding of the non-value adding activities that affect PD and building on Liker and Morgan (2006), Rossi et al. (2011) propose a list of eight types of waste, complemented with 33 examples specific to PD and derived from both literature and practice, grouped into the following macroclasses: over-producing/engineering; waiting; conveyance/ transportation; processing (over/inappropriate); inventory; motion; correction (rework/defective); unused employees' creativity.

In the remainder of this paper we will build on Rossi et al. (2011), since these authors developed a classification that encompasses most of the extant contributions on waste typologies in PD. As a consequence, it can be considered a sound reference point for a study willing to reach a deeper understanding of waste in the context of complex PD projects.

\subsection{Complex projects}

If LPD implementation is challenging for any traditional project, things get more complicated when dealing with complex projects.

According to Baccarini (1996), "project complexity can be defined as consisting of many varied interrelated parts and can be operationalized in terms of differentiation and interdependency" (Baccarini, 1996, p. 202). Furthermore, while the concepts of differentiation and interdependency can be applied to a variety of aspects of the project, the most relevant ones, according to Baccarini, are organizational and technological complexity. Thus, a project can be complex from an 
organizational standpoint if it typically has several units, i.e. departments and teams etc., in charge of specific tasks (organizational complexity by differentiation), whose activities are highly interdependent (organizational complexity by interdependency).

The type of complexity described by Baccarini (1996) was later called "structural complexity" by Williams (1999) who, calling for a new paradigm of project complexity, claims that the latter also depends on the uncertainty and risk that often characterizes the goals of a project and the methods used to achieve them (Daniel and Daniel, 2018; Padalkar and Gopinath, 2016). The discussion on project complexity has been further enriched by the contribution of several authors who have pointed out a number of distinctive characteristics of project complexity.

Vidal et al. (2011) maintain that it relies on four features: project size, project variety, project interdependence and elements of the context. Geraldi et al. (2011) summarize these contributions on project complexity, stating that such a concept can be looked at from five perspectives: structural, uncertainty, dynamics, pace and socio-politics. Turner and Zolin (2012) point out the wide number of stakeholders and different timehorizons of a complex project, which make it necessary to assess its effectiveness through several perspectives.

More recently, academic studies on this topic have highlighted another aspect, which refers to the decision making process peculiar to complex projects, characterized by the typical cognitive and emotional biases that can affect decisions under uncertainty (Daniel and Daniel, 2018; Rezvani et al., 2016; Kahneman, 2011). Such a condition makes it hard to assess complex project's performance and to indentify the cause-effect links between such performance and the adoption of managerial tools and methods.

\subsection{Waste in complex projects}

Project complexity can result in a number of difficulties and related inefficiencies, which keep the company from achieving satisfactory time and cost performance. In fact, complex projects cannot be completely specified in advance, thus leading to evident troubles in the definition of precise technical requirements, a reliable schedule and a precise financial budget (Rezvani et al., 2016; Pfeifer et al., 2015; Ahern et al., 2014; Whitty and Maylor, 2009; Cooke-Davies et al., 2007).

Within this context, uncertainty about the resources and the output, coupled with the technical complexity of the systems to develop, can cause several loops in the development process, which can even result in redundancies considered necessary to ensure the technical perfection of the output. In this regard, evidence is given by Oppenheim et al. (2011), who claim that aerospace and defence programs report up to $90 \%$ of waste, which, however, can be difficult to remove since focusing too heavily on efficiency could increase the level of risk and cause accidents. This is also the case in the naval, chemical, aeronautical and nuclear industries (Browning and Sanders, 2012; Browning and Heath, 2009; Lawson, 2001).
In this kind of environments, redundancies are considered necessary because they help to increase the level of certainty in the project and, as such, they are considered value-adding activities. In this setting, it is hard to understand what waste actually is, because the elimination (or reduction) of some activities in order to cut costs could result in considerable risks for the technical excellence of the project. In fact, as claimed by Browning et al. (2002), p. (454), several stages in the development process aim to produce "information that increases certainty about the ability of the design to meet requirements". Further evidence, in this regard, is brought by Browning and Sanders (2012), who report on a project involving the implementation of lean principles to the F-22 fighter aircraft by Lockheed Martin. Discussing the outcomes of this project, they conclude that an effective implementation of lean management principles in complex projects requires a re-conceptualization of value and waste, since "...activities added to a process serve to catch problems before they cascade through many other activities or increase confidence in the desired result, then they are adding value, despite their characterization as "non-value-adding" by traditional definitions of Lean" (Browning and Sanders, 2012, p. 14).

On the other hand, organizations that manage complex projects characterized by a high degree of technological novelty and complexity tend to overlap the concept of value with the technical perfection of the output. Therefore they regard any project inefficiency as a "necessary evil", the elimination of which could threaten the success of the project (Belvedere and Stringhetti, 2014).

However, even though in the past years several contributions have highlighted the existence of a trade-off between project efficiency and effectiveness in the context of complex projects, more recent studies provide empirical evidence of a positive correlation between these performance categories (Serrador and Turner, 2015; Turner and Zolin, 2012). Thus, appropriate project planning and early controls on stakeholders' needs and requirements, on the one hand, can avoid cost overruns and delays and, on the other, can lead towards superior technical performance (Papke-Shields and BoyerWright, 2017; Davis, 2016; Serrador and Turner, 2015b).

In order to achieve project efficiency, specific approaches must be adopted in complex projects, aimed at strengthening the ability to assimilate and apply new and relevant knowledge, learning from past experience so as to understand which behaviours can positively drive project's performance (PapkeShields and Boyer-Wright, 2017; Heravi and Gholami, A, 2018; Eriksson et al., 2017). For instance, it has been recently demonstrated that good HRM practices can strengthen the positive relationship between absorptive capacity and project's performance (Popaitoon and Siengthai, 2014) and that, more specifically, the presence of absorptive capacity at the teamlevel can partially offset the effect of complex projects' peculiarities on their cost and time performance (Bjorvatn and Wald, 2018).

Thus, it seems to be worthwhile conducting an investigation on the possibility to leverage LPD principles to boost the performance of complex projects, as recent contributions 
demonstrate that managerial practices aimed at increasing efficiency can also lead to favourable results in terms of project's effectiveness.

\section{Research questions and methodology}

\subsection{Research questions}

This paper aims at understanding how the concept of waste can be extended to complex projects and, more specifically, how LPD can be adopted in these environments to remove (or at least reduce) their inefficiencies. In order to achieve this research objective, we built on the extant knowledge on LPD, according to which an organization willing to adopt lean principles must: i) detect its main inefficiencies (so-called "wastes"); ii) plan improvement actions aimed at removing them. Thus we designed our empirical investigation so as to understand:

1. What types of waste, reported so far in the academic literature on LPD, are experienced by employees involved in complex projects;

2. How LPD can be implemented in complex projects to plan sound improvement actions.

Literature on LPD highlights the difficulty of properly identifying the types of waste that can affect the PD process, and this is witnessed by the high number of classifications proposed thus far by researchers specializing in this subject (Rossi et al., 2017; Rossi et al., 2011; Oehmen and Rebentisch, 2010; Locher, 2008; Morgan and Liker, 2006). Furthermore, defining wastes in complex projects can be even more difficult given the fact that, as already pointed out, they generally concern technically complex systems, the development of which may require some redundancies as a means to guarantee their functional perfection (Daniel and Daniel, 2018; Rezvani et al., 2016; Turner and Zolin, 2012; Geraldi et al., 2011; Vidal et al., 2011).

However, the identification of waste in these environments remains a key step in undertaking improvement projects consistent with the principles of LPD, in light of the considerable level of inefficiency that burdens the organizations in which complex projects are managed (Belvedere and Stringhetti, 2014; Browning and Sanders, 2012; Oppenheim et al., 2011).

This problem is particularly relevant in experimental science, which typically involves complex projects, often related to technical instruments, the development of which is spread over many years and is mostly based on in-progress technologies, with a low level of readiness in the early phases of the development process. This is clearly visible in modern experimental astrophysics, both from space, with the development of satellite missions (i.e. JWT), and from the ground, with the design of complex instrumentation such as telescopes (i.e. E-ELT http://www.eso.org/public/teles-instr/e-elt/) (Billings, 2010).

\subsection{Project complexity in modern astrophysics}

In recent decades modern astrophysics has being pushing the boundaries of knowledge to answer ever more complex and challenging questions. This has resulted in increasingly complex projects, which involve a considerable degree of technical complexity, high budgets, large teams of researchers and scientists geographically dispersed over several nations (Honour, 2004).

For example, the European Space Agency's Planck satellite costs $€ 700$ million, involves 400 scientists from 15 countries and is a project spanning 15 years. The Herschel Space Observatory costs $€ 1.1$ billion and the estimated time length of the project is 20 years. The Square Kilometer Array (SKA), a ground based project with the aim of deploying the most powerful telescope ever built, has a budget of $€ 650$ million and will involve $>100$ organizations across 20 countries for the next 50 years (https://www.skatelescope.org). These examples show how the complexity behind new astrophysical research projects has risen. It is thus apparent that astrophysical projects, on the one hand, are by definition "complex" and, on the other hand, require the implementation of best practices aimed at eliminating (or at least reducing) the inefficiencies that lead to considerable delays and extra costs (Locatelli et al., 2014).

In this regard, the adoption of Lean Management principles has been deemed an effective way to improve the timeliness and cost-effectiveness of astrophysical projects, especially when these principles are coupled with Systems Engineering, a discipline that concerns the effective management of complex engineering projects aimed at achieving highly performing technical products (Locatelli et al., 2014; Oehmen, 2012; Oppenheim et al., 2011). However, in these environments the possibility of adopting lean principles may be threatened by the difficulty of identifying non-value adding activities, which may be regarded as necessary redundancies (Belvedere and Stringhetti, 2014).

\subsection{Data collection and analysis}

To answer our research questions, we carried out an empirical study at INAF (the Italian Institute of Astrophysics), a leading Italian institution for astronomy and astrophysics research that performs research studies ranging from the observation of planets and minor bodies of the solar system to cosmology, through ground-based and space-based instrumentation. In 2015 INAF reported 1404 employees, split into four job profiles: researchers (45\%), technologists $(15.5 \%)$, technicians $(26.7 \%)$ and administrative staff $(12.8 \%)$.

The decision to focus on a single organization to conduct our survey was driven by the fact that, according to previous contributions (Belvedere and Stringhetti, 2014; Browning and Sanders, 2012; Oppenheim et al., 2011; Browning and Heath, 2009; Lawson, 2001), when complex projects are run the perception of what is a waste and what is a value-added activity can vary depending on the specificities of the output to be developed. Thus, to collect comparable observations, we 
preferred to focus on a single organization carrying out an extensive survey.

In order to address the above mentioned aims of this research, we carried out a survey targeted to all INAF employees. For this purpose we designed a questionnaire in order to get feedback from the respondents on 4 aspects of each type of waste, as suggested by Rossi et al. (2011):

1. How often does this waste occur in the PD? (P)

2. How serious is this waste? (S)

3. How easy is it to detect this waste in the PD? (D)

4. How avoidable is this waste? (A)

The respondents were requested to check whether each waste was applicable to their projects and, if so, to provide an assessment on a Likert scale from 1 (very low) to 4 (very high) on the four aspects mentioned above. Thus, in cases where a certain type of waste was not applicable to the work performed by the respondent, no answer needed to be given to any of the four questions. This was considered necessary in order to make the most out of the experience (either senior or junior) of target respondents, without taking the risk of biasing our results.

The respondents' answers to the first question provided evidence of whether the most recurrent inefficiencies of INAF's projects match with those reported in the extant literature on LNP. The respondents' feedback on the four aspects enabled us to compute the Priority Index of Intervention (PII) as follows (Rossi et al., 2011):

$P I I=P^{*} S^{*} D^{*} A$

This indicator was used to achieve the aim of identifying a priority list of wastes, so that improvement actions could be planned.

The PII builds on Failure Mode \& Effect Analysis (FMEA) methodology, the origins of which can be traced back to the 1940s when it was adopted for the first time in order to analyze the different root-causes of a product breakdown. FMEA analysis estimates the relative risk associated to each element in the Product Breakdown Structure (PBS) and, then, identifies the priorities of intervention in order to prevent future failures (Stamatis, 2003). Although this methodology was initially used to enable product improvement and is now an integral part of the quality management toolkit and in particular of ISO31010 and QS9000 standards, over time it has been adapted and implemented in a number of different fields, ranging from healthcare services, environmental issues, new product development and project management (Arabian-Hoseynabadi et al., 2010; Chiozza and Ponzetti, 2009; $\mathrm{Hu}$ et al., 2009; Segismundo, 2008; Chuang, 2007; Carbone and Tippett, 2004). In its original version, the quantification of the risk associated with each "failure mode" relies exclusively on 3 dimensions (namely, occurrence, severity and detectability), which drive the Risk Priority Number (Stamatis, 2003). However, we adopted the revised version of such an indicator, as proposed by Rossi et al. (2011). In fact, this approach has already been tested in the field of new product development and the empirical evidence gained so far confirms its ability to correctly prioritize inefficiencies in PD, taking into account not only the traditional 3 dimensions, but also a fourth one, namely the ease of avoiding each failure mode.

In order to design a questionnaire suitable for our survey, we had to describe the main wastes that affect INAF projects. For this purpose we carried out several interviews with experienced researchers and technologists at INAF, each lasting on average $1 \mathrm{~h}$. We used a research protocol according to which the interviewees were first of all requested to describe the main inefficiencies that they encounter in their projects. Then, once this open question was answered, the interviewees were requested to discuss the relevance in their activities of the wastes as described by Rossi et al. (2011) and to give examples of cases in which such wastes occurred. This was considered necessary in order to make the interviewees think of other possible inefficiencies specific to their projects, which could resemble the wastes reported in LPD literature. In this stage of the research we built on Rossi et al. (2011) since such taxonomy encompasses most of the waste typologies proposed in previous studies (Oehmen and Rebentisch, 2010; Morgan and Liker, 2006; Ohno, 1988) and, as a consequence, it can be considered the most exhaustive one.

Overall we carried out 14 interviews, namely 12 researchers and 2 technologists, selected on the basis of their long-term experience as project managers at INAF. The interviews regarded projects characterized by a high degree of complexity and concerning (among the others) several areas such as: the development of a radio telescope for a major international astrophysical project; long-term data analysis within space missions; technological development of coolers for satellites; development of the electronic system embedded into satellites; development of an interferometer; research and development of detectors.

After 14 interviews, we realized that the examples and types of inefficiencies described by the interviewees tended to converge. Thus, following the instructions of Yin (2003) for qualitative research studies, we decided not to conduct any further interviews and to start analyzing the available information. All interviews were recorded and transcribed, so that their content could be analyzed, with the aim of identifying a meaningful unit of contents, which related to the wastes described by the interviewees (Krippendorff, 2013). Then, on the basis of this outcome, we came up with 104 descriptions of inefficiencies, which were used as a starting point to design the first draft of the questionnaire for the survey. This draft was shared with all the interviewees so as to get their feedback on the way in which such wastes were described in our document and their perception of the time necessary to complete the questionnaire (Hensley, 1999).

The pilot test of the survey, run with the interviewees, highlighted several redundancies in the description of the wastes due to the considerable degree of similarity among some questionnaire items, as well as some wording issues, related to the fact that some descriptions were unclear. On the basis of this feedback, and together with the interviewees, we re-worded 
some unclear statements and removed redundant waste descriptions. This process led us to reduce the initial list from 104 wastes down to 41 (see Table 1), making it more understandable and time-efficient.

Building on the 41 wastes described in Table 1, we developed the questions of our survey, asking for each waste whether it was encountered during the professional experience of the respondent. If so, he/she was asked to provide an assessment on a Likert scale from 1 (very low) to 4 (very high) on the four distinctive aspects of the PII. An example of such questions for some wastes and of the way in which we labelled the variables is reported in Appendix 1.

The final version of the questionnaire was administered to all INAF employees using a web-based system. A total number of 159 usable questionnaires was collected, with a redemption rate of $11 \%$.

The mean age of the respondents was 45.4 years, with an average of 15.4 years of experience at INAF. Their current position was as follows: researchers (63.5\%), technologists (11.3\%), technicians $(22.6 \%)$ and administrative staff $(2.5 \%)$.

\section{Empirical results}

\subsection{Waste categories}

The wastes identified through our interviews and reported in Table 1 show that most of the inefficiencies of INAF's projects are consistent with the classification of the PD waste types

Table 1

Questionnaire items and waste descriptions.

\begin{tabular}{|c|c|c|}
\hline $\begin{array}{l}\text { Variable } \\
\text { No. }\end{array}$ & Waste description & $\begin{array}{l}\text { Waste Categories (Rossi et al., } \\
\text { 2011) }\end{array}$ \\
\hline V1 & Excessive requirements are set compared to the real needs of the project. & Overproduction/processing \\
\hline $\mathrm{V} 2$ & Requirements are frequently changed throughout the project. & Overproduction/processing \\
\hline V3 & Requirements are too generic. & Overproduction/processing \\
\hline V4 & The activities in a work plan are not defined correctly. & - \\
\hline V5 & $\begin{array}{l}\text { Similar projects of data analysis with the same scientific objectives are carried out in parallel without any } \\
\text { coordination. }\end{array}$ & Inventory \\
\hline V6 & Emails do not report complete information. & Overproduction/processing \\
\hline V7 & Emails are sent to people not in charge of the activity that the information refers to. & - \\
\hline V8 & Hiring procedures are slow. & Waiting \\
\hline V9 & Funds for hiring are inadequate. & Waiting \\
\hline V10 & The resources available to acquire new staff are scarce. & - \\
\hline V11 & Bureaucracy is too slow compared to the needs of the projects. & Waiting \\
\hline V12 & Funds obtained through a tender are not delivered quickly & Waiting \\
\hline V13 & Procurement procedures are too slow. & Waiting \\
\hline V14 & Travel arrangements are delegated to the researcher. & - \\
\hline V15 & The management of all bureaucratic aspects of a project is delegated to the researcher. & - \\
\hline V16 & Project milestones are frequently postponed. & - \\
\hline V17 & Decisions are postponed until the approach of project milestones. & - \\
\hline V18 & There is a lack of decision making power inside the project team. & - \\
\hline V19 & The lack of financing leads researchers and technicians to always be in "proposal mode". & Inventory \\
\hline V20 & Hardware is frequently moved among different laboratories. & Transportation \\
\hline V21 & Hardware tests are performed even when they are not strictly necessary. & Overproduction/processing \\
\hline V22 & Requirements are not adequately formalized. & Overproduction/processing \\
\hline V23 & Projects are often not completed. & Inventory \\
\hline V24 & Projects with similar objectives are carried out simultaneously without any coordination. & Inventory \\
\hline V25 & The fragmentation of research among different centres involves many transfers. & Motion \\
\hline V26 & Physical meetings are preferred to virtual ones (e.g. videoconference). & Motion \\
\hline V27 & Meetings take place too often compared to the real needs of the project. & Motion \\
\hline V28 & Too few meetings take place compared to the real needs of the project. & - \\
\hline V29 & The number of participants to project meetings is excessive. & - \\
\hline V30 & Tests are frequently repeated. & Correction \\
\hline V31 & Analyses are repeated because controversial results cannot be traced. & Correction \\
\hline V32 & Similar researches are carried out by different groups without proper knowledge sharing. & Unused Employee Creativity \\
\hline V33 & Competition among different groups does not allow knowledge sharing. & - \\
\hline V34 & Lessons learnt from the project are never shared. & - \\
\hline V35 & The organization does not exploit the lessons learnt from the projects. & - \\
\hline V36 & People are not assigned to a project because of their competences but because in that moment they are available. & Unused Employee Creativity \\
\hline V37 & $\begin{array}{l}\text { The lack of a database on the organization's internal competences does not allow for a full exploitation of the human } \\
\text { capital. }\end{array}$ & Unused Employee Creativity \\
\hline V38 & It is impossible to retain young researchers and technicians. & Unused Employee Creativity \\
\hline V39 & The managerial competences gained by researchers and technicians are not adequately remunerated. & Unused Employee Creativity \\
\hline V40 & Roles within the team are not well defined. & Unused Employee Creativity \\
\hline V41 & The compensation system at INAF does not incentivize employees' commitment. & Unused Employee Creativity \\
\hline
\end{tabular}


mentioned in the literature on this topic, although they need to be tailored on the specificities of astrophysical projects. The last column of Table 1 highlights that most waste descriptions are examples of the types proposed by Rossi et al. (2011), which we built on. However, it can also be seen that some other waste descriptions do not match with the standard classification, and this represents a first contribution to the body of knowledge of PD waste within complex systems management. Thus, we performed a factor analysis to properly group our waste descriptions into meaningful macro-classes, leveraging also the INAF's waste types that did not match with any existing category reported in extant literature.

The factor analysis, carried out according to the instructions of Hair et al. (2006), was performed on the answers provided to the first question concerning each type of waste (i.e. variables from V1_1 to V41_1, aimed at measuring answers to the following type of question: How often does this waste occur in the PD?, see Appendix 1). This choice (i.e. focusing just on the this question) was due to the fact that, at this stage, we wanted to highlight the waste categories that occur more frequently, regardless of the effect they can have on the projects carried out at INAF.

A total number of 7 relevant waste macro-classes emerged from the factor analysis, the details of which are provided in Appendix 2 and described below.

The first macro-class has been called Overproducing/Overengineering since it encompasses 5 wastes, mostly related to inefficiencies concerning the definition of project requirements, which are frequently excessive, not very precise and change during the life-time of the project. These problems are clearly highlighted by the first 3 questionnaire items that are relevant to this factor (V1_1, V2_1, V3_1). Also the fourth and fifth items (V6_1, V7_1) contribute to the description of this construct, although they do not explicitly mention "requirements". Indeed, these two items refer to some possible "reasons why" overproducing/over-engineering takes place, i.e. poor communication that leads, on the one hand, to providing team members with inaccurate/incomplete information and, on the other hand, to involving people in the communication process that are not in charge of the activity that the information refers to.

The second macro-class has been called Project Vision Waste and it is described by 5 questionnaire items, referring to the poor planning of project milestones and the inability to leverage the "lessons learnt" from previous projects (Ahern et al., 2014). Although this factor does not seem to explicitly match with any of the waste types reported in the extant literature on LPD, it nevertheless describes a problem that was frequently mentioned during the interviews carried out at INAF. In fact, the researchers interviewed pointed out the inability of their organization to develop reliable schedules, which results in frequent and significant delays (V16_1, V17_1). Furthermore, as mentioned in Section 3.2, poor project schedule adherence is a major inefficiency in this sector that can be only partially attributed to the inherent complexity of astrophysical projects and the difficulty of setting precise and stable requirements for technical equipment. An inadequate focus on project planning and, in some cases, the lack of know- how and tools suitable for supporting this process might result in delays, the duration of which can often be measured in years (Browning, 2014; Van de Vonder et al., 2005).

Also in this case, the questionnaire items that are relevant to this factor seem to provide an insight into the "reasons why" these problems occur. An unclear definition of roles and responsibilities in the project team appears as one possible cause, as witnessed by variable V29_1 that makes an explicit reference to the excessive number of participants in team meetings, which is generally one of the outcomes of a poorlymanaged project. Moreover, variables V35_1 and V34_1 express the inability of the organization to leverage previous experiences that, in this setting, can highlight an overall underestimation of project timeliness.

The third macro-waste resulting from the factor analysis has been called Inventory. The four variables that are relevant to this factor recall problems related to the fact that projects are often not completed (V23_1), while some others with the same scientific objectives are carried out in parallel due to the poor coordination of researchers that hence does not allow for knowledge sharing (V5_1, V24_1, V32_1). More broadly, this factor highlights the inability of the organization to identify key research objectives that it should pursue through an efficient allocation of its resources, especially human resources. This results in incomplete or unnecessary projects, which are reminiscent of the idea of a "stock" of semi-finished research activities or of redundant research outcomes. This evidence confirms the relevance of "inventory" as waste specific to PD, since the way in which this construct is described by the bundle of variables is consistent with the extant contributions on wastes in PD and in particular on "inventory" as a waste type (Rossi et al., 2011).

The fourth macro-class, called Waiting, is made up of 5 types of waste that concern bureaucratic issues, namely related to sourcing and hiring procedures (V8_1, V9_1, V11_1, V12_1, V13_1). Although these statements are not related to the core activities of the development project, they confirm that bureaucratic inefficiencies determine some forms of "waiting" that can negatively influence the timeliness of researchers' activities and, thus, the overall time performance of the project.

The fifth macro-class, Unused employee creativity, encompasses two questionnaire items (V36_1, V40_1) concerning the inability of the organization to properly leverage its personnel. This type of waste is consistent with previous contributions, which highlight the relevance of human resources for the success of projects in PD environments (Rossi et al., 2011).

The sixth macro-class, Hardware Overprocessing, includes 2 wastes related to the excessive amount of transportation and technical equipment testing (V20_1, V21). On the one hand, this waste type is consistent with the specific nature of the environment under analysis, where it is actually very frequent to observe the transportation of technical equipment due to the need to perform tests that can be carried out only in specific laboratories. On the other hand, the value-destroying potential of an excessive number of controls is consistent with extant literature on overprocessing. This evidence is further confirmed 
Table 2

PII: average values for each waste macro-class.

\begin{tabular}{|c|c|c|c|c|c|c|c|c|}
\hline & $\begin{array}{l}\text { F1 - Overproducing/ } \\
\text { Overengineering }\end{array}$ & $\begin{array}{l}\mathrm{F} 2 \text { - Project } \\
\text { Vision Waste }\end{array}$ & $\begin{array}{l}\text { F3 - } \\
\text { Inventory }\end{array}$ & $\begin{array}{l}\text { F4 - } \\
\text { Waiting }\end{array}$ & $\begin{array}{l}\text { F5 - Unused } \\
\text { Employee Creativity }\end{array}$ & $\begin{array}{l}\text { F6 - Hardware } \\
\text { Overprocessing }\end{array}$ & F7 - Correction & P-value \\
\hline PII & $\begin{array}{l}26.7 \\
n=159\end{array}$ & 27.6 & 21.6 & 40.3 & 36.9 & 9.4 & 22.1 & $<0.000$ \\
\hline
\end{tabular}

by the seventh waste macro-class, Correction, which includes 2 items referring to the problem of redundancy of the tests and analyses in a broader sense (V30_1, V31_1).

The factor analysis highlights waste types that, for the most part, are similar to those of previous studies on this topic (Rossi et al., 2011). This evidence shows that the broad concept of "waste" specific to the literature on LPD can also be applied in organizations characterized by complex projects, even though waste descriptions must be tailored on the specificities of such organizations in order to properly capture their main inefficiencies.

\subsection{Improvement priorities}

In order to identify the areas that, according to the respondents, need to be improved more than others, we computed the PII for each waste macro-class. In order to get this number, first of all we computed the PII of every single waste belonging to the macro-class. For instance, focusing on waste V1, the PII was obtained as follows (see Appendix 1 for the meaning of the variables' labels):

$$
P I I{ }_{V 1}=V 1_{-} 1^{*} V 1 \_2^{*} V 1 \_3^{*} V 1 \_4
$$

Then, for each macro-class we computed the simple average of the PIIs of the wastes belonging to it. The average values are reported in Table 2.

Surprisingly, the highest PIIs are those reported by F4 and F5, i.e. Waiting and Unused Employee Creativity, which concern administrative and human resource management problems, even though during the interviews they were regarded as less relevant than other inefficiencies, namely those concerning project requirements such as Overproducing and Over-Engineering.

An ANOVA was carried out, the outcomes of which demonstrate that differences among average values of PIIs are statistically significant at $p$-value $<.000$. Furthermore, we controlled the impact of some variables on the PIIs, namely job profile, type of contract, age of the respondent and length of time working at INAF. None of these played a significant role in driving the PII. Thus it can be claimed that these control variables actually do not influence the PII.

Furthermore, in order to have a deeper insight into the drivers of the PII, we also analyzed its four determinants (i.e. Probability, Severity, Detectability and Avoidability, also labelled $V_{-} 1, V_{-}$, $V \_3, V \_4$ in Appendix 1). Table 3 reports the average values of PII's determinants for each waste macro-class.

Also in this case an ANOVA analysis was carried out in order to check whether differences among the four means specific to each waste macro-class were statistically significant. For all cases a $p$-value lower than 0.001 was observed, which confirms the statistical significance of such differences.

Also in this case the highest scores for all four determinants of the PII are those reported by Unused Employee Creativity and Waiting, with the only exception of Question 3 (Detectability), where Waiting ranks third.

Furthermore, it can be noted from Fig. 1 below that the patterns of the average values of Probability, Severity, Detectability and Avoidability are very similar to one another, thus suggesting the possibility of a high correlation between such values.

Indeed, this is confirmed by the computation of the correlation coefficients, which in most cases are higher than 0.5 and in all cases are highly-significant from a statistical viewpoint $(p$-value $<.001)$. Moreover, it is worth noting that Avoidability (V_4) is highly correlated in particular with the perceived Severity (V_2). This could be interpreted as a low level of tolerance on the part of the respondent (implicitly measured through Severity - V_2) towards the types of waste that in his/her opinion could be easily removed (explicitly measured through Avoidability - V_4).

The evidence concerning the PII, coupled with the high correlations between its determinants, suggests a possible

Table 3

Wastes Macro-classes: average values of the PII's determinants.

\begin{tabular}{|c|c|c|c|c|c|}
\hline Waste Macro-Class & $\begin{array}{l}\text { Probability } \\
\text { V_1 }\end{array}$ & $\begin{array}{l}\text { Severity } \\
\mathrm{V} \_2\end{array}$ & $\begin{array}{l}\text { Detectability } \\
\text { V_3 }\end{array}$ & $\begin{array}{l}\text { Avoidability } \\
\text { V_4 }\end{array}$ & P-value \\
\hline F1 - Overproducing/Over-engineering & 1.6 & 2.1 & 1.7 & 2.0 & $<0.001$ \\
\hline F2 - Project Vision Waste & 1.8 & 2.1 & 1.7 & 1.8 & $<0.001$ \\
\hline F3 - Inventory & 1.7 & 2.1 & 1.8 & 1.9 & $<0.001$ \\
\hline F4 - Waiting & 2.9 & 3.1 & 1.7 & 2.2 & $<0.001$ \\
\hline F5 - Unused Employee Creativity & 2.2 & 2.7 & 1.9 & 2.2 & $<0.001$ \\
\hline F6 - Hardware Overprocessing & 0.7 & 1.0 & 1.0 & 1.1 & $<0.001$ \\
\hline F7 - Correction & 1.4 & 1.7 & 1.6 & 1.7 & $<0.001$ \\
\hline
\end{tabular}




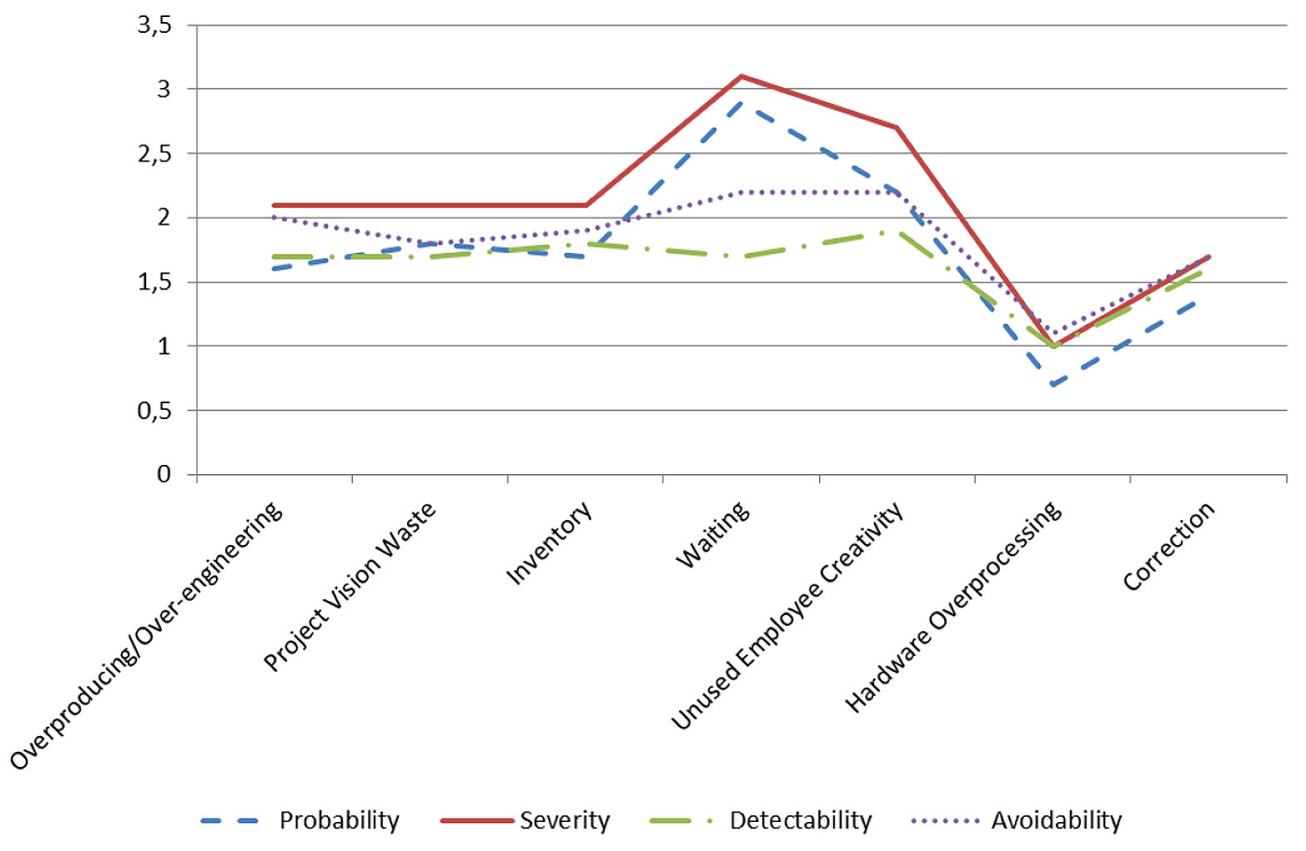

Fig. 1. Wastes Macro-classes: average values.

"common method bias", which is likely to occur when respondents provide a sort of "automatic" response (equal or similar for all questions concerning a certain phenomenon) because he/she has an emotional bias (Podsakoff et al., 2003). In this case, if the respondent thinks that a problem seriously affects his/her job, he/she may claim that it happens very often, that it is very serious, and that it could be detected and removed very easily. Appendix 3 provides statistical evidence on the fact that this bias actually affects the opinions of the respondents.

Overall, the empirical evidence resulting from the survey seems to demonstrate that, while wastes specific to LPD also exist in an organization such as INAF, where complex projects are carried out, it is actually difficult to leverage the experience of its employees to define a reliable priority list suitable for planning improvement actions. In fact, the answers provided by the respondents seem to be biased. Furthermore, looking at the average value of the PIIs (see Table 2), it could be claimed that in such an organization, which encounters problems such as poor project planning and poor definition of requirements (factors that may have a dramatic effect on the timeliness and cost-effectiveness of the project), the most relevant priority (in the eyes of the respondents to the survey) refers to the solution of bureaucratic problems, like speeding up the sourcing process for commodity services, while the second major area of improvement refers to human resources management processes. On the other hand, problems such as those described by Project Vision Waste and Overproducing/Overengineering have a much lower score, even though projects carried out in organizations running astrophysical projects are frequently affected by significant delays and poorly specified requirements. It is also apparent that Waiting and Unused Employee Creativity refer to processes that are beyond the scope of responsibility of the researcher, which seems to witness a higher degree of tolerance towards the inefficiencies specific to the research and development activities.

In order to further investigate this evidence, the outcomes of the content analysis on the interviews was leveraged, so as to compute the frequency with which wastes (grouped according to the outcomes of the factor analysis) were mentioned by the 14 interviewees (Krippendorff, 2013). Such frequencies are reported in Table 4.

In Table 4 it can be seen that the most significant issues, at least in terms of frequency, are Project Vision Waste, followed by Overproducing/Overengineering, while Waiting and Unused Employee Creativity rank fourth and fifth respectively, despite being in the top positions according to the PII (see Table 2). Even though the ranking described in Table 4 is based on the frequency with which waste macro-classes have been mentioned during the interviews, it is still possible to claim that this frequency can be considered a proxy of the relevance attributed by the interviewees to such inefficiencies. Indeed, during the 14 interviews it was apparent that the number of examples given for each waste macro-class was in line with the

Table 4

Frequency of waste types in the interviews.

\begin{tabular}{ll}
\hline Waste Macro-Class & Frequency (\%) \\
\hline F1 - Overproducing/Over-engineering & 22.7 \\
F2 - Project Vision Waste & 29.5 \\
F3 - Inventory & 13.6 \\
F4 - Waiting & 11.4 \\
F5 - Unused Employee Creativity & 11.4 \\
F6 - Hardware Overprocessing & 6.8 \\
F7 - Correction & 4.5 \\
\hline
\end{tabular}

$\mathrm{n}=159$. 
perceived severity of the problem, and the variety of cases experienced by the researchers demonstrated the critical nature of the main types of inefficiencies. This was the case in overengineering. According to several interviewees, this inefficiency is mostly due to the challenging research objectives of the Principal Investigator, involving extremely advanced pieces of equipment with poorly-specified requirements in the early stages of the project.

However, this evidence was obtained through a dialectic process, where the interviewees were asked, after an open discussion on project inefficiencies, to focus more on the waste types described in LPD literature. During this process, the interviewees gained an increasingly higher degree of awareness of the relevance of some inefficiencies, proving the effectiveness of the method (Rossi et al., 2011) we used not only to identify waste types and prioritize them, but also to create awareness on the part of practitioners of the concept of waste that -in PD- is of crucial importance since, to date, it has been understudied.

\section{Discussion}

Through this empirical investigation we aimed at contributing to the discussion on the relationship between efficiency and effectiveness in complex projects, with the specific purpose of understanding whether LPD can be adopted to identify and remove their "waste", while producing favourable results also on the effectiveness of the project (Papke-Shields and BoyerWright, 2017; Davis, 2016; Serrador and Turner, 2015; Serrador and Turner, 2015b; Turner and Zolin, 2012).

More specifically, our first research question aimed at understanding what types of waste are experienced by employees involved in complex projects. On the basis of the outcomes of this study, it can be stated that the waste types described in extant literature on LPD can also be found in complex projects. In fact, the waste macro-classes highlighted in our study seem to be consistent, for the most part, with those reported in previous contributions, and in particular with Rossi et al. (2011), which we built on, even though some waste descriptions encompassed in the macro-classes are tailored to the specific nature of INAF's activities. On top of the existing types, our empirical investigation also highlights the relevance of a further area of concern that has been called "Project Vision Waste", related to the difficulty with which complex projects can be planned and their deadlines met.

Thus, LPD could be considered an effective and appropriate methodology to address project inefficiencies that hinder the achievement of satisfactory time and cost performance. Furthermore, it is demonstrated that some inefficiencies that heavily affect project's effectiveness (namely overproducing/ over engineering) are captured by the LPD taxonomy of wastes. Thus, it can be claimed that LPD not only can support organizations in highlighting (and then removing) their inefficiencies, but it can also help in identifying and addressing problems that can jeopardize the ability of the project's output to meet stakeholders needs.
Concerning the second research question, i.e. how LPD can be implemented in complex projects to plan sound improvement actions, our study points out some risks associated with the adoption of standard LPD tools. Indeed, we demonstrate that the perception of the relevance of waste in complex projects can be highly biased, so that a tool such as the Priority Index of Intervention (PII), which has proven to be effective in standard PD projects (Rossi et al., 2011), cannot lead to the definition of a reliable and sound list of priorities for possible improvement actions. This evidence is in line with extant literature, according to which the application of lean principles to complex projects needs some "caveats", particularly concerning the re-conceptualization of waste (Browning and Sanders, 2012), which is the starting point for understanding where and how to pursue a higher degree of efficiency. This evidence is also consistent with recent contributions that have highlighted a new distinctive feature of complex projects, concerning their decision making process, which are characterized by the typical cognitive and emotional biases that can affect decisions under uncertainty (Daniel and Daniel, 2018; Rezvani et al., 2016; Kahneman, 2011).

As a consequence of this biased decision making, while for some waste categories (like the Waiting type highlighted in this paper) the adoption of standard lean principles and tools can be straightforward (e.g. streamlining the sourcing process of commodity services), it is difficult for researchers to realize the inherent inefficiency of some activities (e.g. project scheduling, requirement specification etc.) in which the use of appropriate managerial methods could result in considerable improvements (Daniel and Daniel, 2018; Belvedere and Stringhetti, 2014).

In order to overcome this obstacle, the organization of workshops is recommended as an effective tool for increasing the level of researchers' awareness of the major wastes that affect their projects. The results of this study were in fact presented during two seminars organized in two of INAF's main premises, in order to share the main outcomes and encourage a discussion on the need to increase project efficiency. Although these workshops were only a "starting point", nonetheless they were successful in that attendees understood the need to start this discussion.

This is consistent with the evidence reported in Baujard et al. (2010), who described the "Lean Journey" of an aerospace company in the engineering process. Also in this case, the "journey" started with the organization of a workshop on the project and the identification of the team members, selected from employees who had already worked in similar projects so that their "lessons learnt" could be exploited. However, while Baujard et al. (2010) suggest the "description of the current state" as a second step, taking it for granted that researchers are able to assess the relevance of the different types of project wastes, we believe that before starting with the mapping of the "current state", it is necessary to define the perimeter of all relevant waste types. Within this perimeter, the wastes that do not fall within the scope of responsibility of the researcher (such as those classified in the Waiting and Unused Employees' Creativity) 
should be explicitly excluded so that team members can focus on the most critical inefficiencies.

Furthermore, while the use of tools like the PII is frequent and comes highly recommended, such as by Baujard et al. (2010), our study points out the need to use a "dialectic approach" based on seminars and workshops aimed at stimulating an unbiased description of the major inefficiencies encountered by researchers in their previous projects, in order to reach a deep understanding of their outcomes and root-causes and to enhance the level of awareness of their actual relevance. The evidence resulting from such initiatives should be the starting point of a further step, which consists of producing a priority list of actions to be taken, on the basis of the procedure discussed above and based on the computation of the PII.

In order to enable researchers to understand the actual relevance of the various types of project waste, workshops could even be extended to members of other institutions or agencies that have already implemented such processes. In addition, visiting the sites of these institutions could be beneficial in order to gain a deeper understanding of lean management in complex projects and, more specifically, of the types of waste that were primarily addressed. This is a common best practice used in the past by many different agencies (e.g. ESO), which organize visits to advanced laboratories in order to learn lessons from other people: steal from the best.

\section{Conclusions, limits and future research directions}

This paper reports the findings of a study carried out at INAF, the Italian Institute of Astrophysics, in an attempt to understand how the knowledge developed thus far in the literature on LPD in relation to waste detection and elimination can be leveraged also in complex projects.

The evidence resulting from this study demonstrates that the main types of waste reported in extant literature can be observed also in complex projects. Furthermore, some other types, specific to complex projects carried out at INAF, were highlighted by our study. Therefore, it can be argued that the adoption of methods, such as Lean Product Development, can be leveraged to address problems specific to these environments, for example poor project schedule adherence and significant extra-costs.

This evidence makes a contribution to the field of study concerning the relationship between efficiency and effectiveness in complex projects, providing evidence about the fact that the former could be pursued through LPD without jeopardizing the latter. Indeed, our study shows that some major problems that can lead not only to poor efficiency but also to poor effectiveness (in particular over engineering/over requirement) are captured by the standard taxonomies of waste used in LPD.

However, this study also points out a serious obstacle in the adoption of lean principles, which concerns the difficulty with which researchers involved in these projects assess the priority of the actions to be taken in order to reduce the wastes detected.
This outcome is consistent with previous contributions, according to which some redundancies are necessary in order to reduce the degree of risk inherent to complex projects. This makes the distinction between value-adding activities and "waste" much harder than in more repetitive and stable processes. Our study contributes to this discussion, highlighting the fact that researchers seem not to perceive the relevance of addressing inefficiencies generated by their own work, while placing considerable attention on waste types that are beyond the scope of their direct responsibilities. This phenomenon seems to witness a low perception of the improvement opportunities in the management of complex research projects, where the adoption of appropriate methods and logics could bring about notable benefits.

This evidence is in line with other recent contributions which have focused on the peculiarities of the decision making process under uncertainty (peculiar to complex projects), which is influenced by a number of biases that organizations should try to overcome. In this regard, a cultural shift among researchers and scientists has to be pursued, through appropriate training programs.

Some limits of our study can be highlighted. The main one relies on the fact that our research focuses on an organization with its own peculiarities; thus we cannot say whether the evidence stemming from this analysis can be extended to other institutions that run complex projects.

A further limit refers to the fact that our questionnaire did not explicitly aim at describing the specific biases that can affect the management of complex projects. Indeed, the presence of a biased decision making process is an evidence of the joint analysis of the interviews and of the survey data.

To overcome the limits reported above, it would be worthwhile replicating this study in similar organizations of the aerospace/astrophysics in order to check whether our conclusions can be generalized to the whole industry. Furthermore, the same analysis could be conducted in other organizations that run complex projects but that do not belong to the astrophysical sector, in order to understand whether and to what extent wastes in complex projects can be "industry-specific".

Moreover, since an evidence of our study refers to the fact that the decision making process in complex projects seems to be biased, future studies could aim at properly describing such cognitive distortions and at identifying, through the study of "best-in-class" organizations, solutions adopted to "debias" the process.

Finally, it would be worthwhile understanding whether initiatives - as workshops, seminars and visits to more advanced institutions - can actually enhance the level of researchers' awareness of the most relevant inefficiencies of their projects. To test the effectiveness of these programmes, it could be useful to understand whether the perceived importance attributed to wastes affecting the organization change before and after the training. 
Appendix 1. Questions for each waste and labels of the variables: an example

\begin{tabular}{|c|c|c|c|c|}
\hline & $\begin{array}{l}\text { How often does this waste } \\
\text { occur in PD? (P) } \\
\text { V_1 }\end{array}$ & $\begin{array}{l}\text { How serious is this waste for } \\
\text { your work? (S) } \\
\text { V_2 }\end{array}$ & $\begin{array}{l}\text { Can this waste be easily } \\
\text { detected? (D) } \\
\text { V_3 }\end{array}$ & $\begin{array}{l}\text { Can this waste be easily } \\
\text { avoided? (A) } \\
V_{-} 4\end{array}$ \\
\hline $\begin{array}{l}\text { V1: Excessive requirements are set compared } \\
\text { to the real needs of the project. }\end{array}$ & V1_1 & V1_2 & V1_3 & V1_4 \\
\hline $\begin{array}{l}\text { V2: Requirements are frequently changed } \\
\text { throughout the project. }\end{array}$ & V2_1 & V2_2 & V2_3 & V2_4 \\
\hline$\ldots$ & $\ldots$ & $\ldots$ & $\ldots$ & $\ldots$ \\
\hline
\end{tabular}

\section{Appendix 2. Wastes Macro-classes: Cronbach's Alpha and factor loadings}

Following Hair et al. (2006), we retained only those factors characterized by an Eigenvalue higher than 1 and a Cronbach's Alpha higher than (or equal to) 0.6 (Nunnally, 1978). In order to interpret the meaning of each factor, we considered only the questionnaire items with a factor loading higher than 0.5 for one factor only (Hair et al., 2006; Hu and Bentler, 1999; Stevens 1986). A total number of 7 relevant waste macro-classes emerged from this analysis, which account for 54\% of the total variance of the phenomenon.

\begin{tabular}{|c|c|c|c|c|c|c|c|}
\hline & $\begin{array}{l}\text { F1 - Overproducing/ } \\
\text { Overengineering }\end{array}$ & $\begin{array}{l}\text { F2 - Project } \\
\text { Vision Waste }\end{array}$ & $\begin{array}{l}\text { F3 - } \\
\text { Inventory }\end{array}$ & $\begin{array}{l}\text { F4 - } \\
\text { Waiting }\end{array}$ & $\begin{array}{l}\text { F5 - Unused } \\
\text { Employee Creativity }\end{array}$ & $\begin{array}{l}\text { F6 - Hardware } \\
\text { Overprocessing }\end{array}$ & $\begin{array}{l}\text { F7 - } \\
\text { Correction }\end{array}$ \\
\hline $\begin{array}{l}\text { Cronbach's } \\
\text { Alpha }\end{array}$ & 0.822 & 0.813 & 0.738 & 0.767 & 0.600 & 0.740 & 0.778 \\
\hline V1_1 & 0.808 & & & & & & \\
\hline V2_1 & 0.789 & & & & & & \\
\hline V3_1 & 0.771 & & & & & & \\
\hline V6_1 & 0.752 & & & & & & \\
\hline V7_1 & 0.706 & & & & & & \\
\hline V16_1 & & 0.806 & & & & & \\
\hline V17_1 & & 0.804 & & & & & \\
\hline V29_1 & & 0.765 & & & & & \\
\hline V35_1 & & 0.760 & & & & & \\
\hline V34_1 & & 0.645 & & & & & \\
\hline V5_1 & & & 0.782 & & & & \\
\hline V23_1 & & & 0.779 & & & & \\
\hline V24_1 & & & 0.739 & & & & \\
\hline V33_1 & & & 0.700 & & & & \\
\hline V8_1 & & & & 0.792 & & & \\
\hline V9_1 & & & & 0.747 & & & \\
\hline V11_1 & & & & 0.741 & & & \\
\hline V12_1 & & & & 0.674 & & & \\
\hline V13_1 & & & & 0.641 & & & \\
\hline V36_1 & & & & & 0.845 & & \\
\hline V40_1 & & & & & 0.841 & & \\
\hline V20_1 & & & & & & 0.891 & \\
\hline V21_1 & & & & & & 0.785 & \\
\hline V30_1 & & & & & & & 0.906 \\
\hline V31_1 & & & & & & & 0.852 \\
\hline
\end{tabular}

\section{Appendix 3. Harman Single Factor test: evidence for the seven waste macro-classes}

The Harman Single Factor test (Harman, 1967) requires that a factor analysis is carried out. If one single factor emerges that explains $>50 \%$ of the variability of phenomenon, the common method bias is likely to happen. Thus, for each waste macro-class, we carried out a factor analysis on all questionnaire items peculiar to it, including the answers to all of the four questions asked for each waste. For all waste macro-classes, this analysis generated one single factor that accounts for $>50 \%$ of the Variance Explained (see Table A1 below). It is thus evident that the respondents are affected by the common method bias, which is most likely due to their emotional approach to the assessment of the PD wastes. 


\begin{tabular}{lc}
\hline Waste Macro-Class & Variance Explained by 1 Single Factor (\%) \\
\hline F1 - Overproducing/Over-engineering & 82.2 \\
F2 - Project Vision Waste & 86.0 \\
F3 - Inventory & 79.9 \\
F4 - Waiting & 57.6 \\
F5 - Unused Employee Creativity & 71.1 \\
F6 - Hardware Overprocessing & 91.7 \\
F7 - Correction & 87.9
\end{tabular}

\section{References}

Ahern, T., Leavy, B., Byrne, P.J., 2014. Complex project management as complex problem solving: a distributed knowledge management perspective. Int. J. Proj. Manag. 32 (8), 1371-1381.

Arabian-Hoseynabadi, H., Oraee, H., Tavner, P.J., 2010. Failure modes and effects analysis (FMEA) for wind turbines. Int. J. Electr. Power Energy Syst. 32 (7), 817-824.

Baccarini, D., 1996. The concept of project complexity—a review. Int. J. Proj. Manag. 14 (4), 201-204.

Bandecchi, M., Melton, B., Gardini, B., Ongaro, F., 2000. The ESA/ESTEC concurrent Design Facility. Proc. EUSEC 9, 2000.

Baujard, M., Gilles, H., Terrien, O., 2010. An Experience Report at Thales Aerospace: The Lean Journey, THALES Internal Report.

Belvedere, V., Stringhetti, L., 2014. Can lean systems engineering enhance the value of astrophysical projects. Hum. Syst. Manag. (33), 99-111.

Billings, L., 2010. Space science: the telescope that ate astronomy. Nature 467, 1028-1030.

Bjorvatn, T., Wald, A., 2018. Project complexity and team-level absorptive capacity as drivers of project management performance. Int. J. Proj. Manag. 36 (6), 876-888

Browning, T.R., 2014. Managing complex project process models with a process architecture framework. Int. J. Proj. Manag. 32 (2), 229-241.

Browning, T.R., Heath, R.D., 2009. Reconceptualizing the effects of lean on production costs with evidence from the F-22 program. J. Oper. Manag. 27 (1), 23-44

Browning, T.R., Sanders, N.R., 2012. Can Innovation be Lean? Calif. Manag. Rev. 54 (4), 5-19.

Browning, T.R., Deyst, J.J., Eppinger, S.D., Whitney, D.E., 2002. Adding Value in Product Development by Creating Information and reducing risk. IEEE Trans. Eng. Manag. 49 (4), 443-458.

Carbone, T.A., Tippett, D.D., 2004. Project risk management using the project risk FMEA. Eng. Manag. J. 16 (4), 28-35.

Chiozza, M.L., Ponzetti, C., 2009. FMEA: a model for reducing medical errors. Clin. Chim. Acta 404 (1), 75-78.

Chuang, P.T., 2007. Combining service blueprint and FMEA for service design. Serv. Ind. J. 27 (2), 91-104.

Clark, K.B., Chew, W.B., Fujimoto, T., 1987. Product Development in the World Auto Industry. Brook. Pap. Econ. Act. (3), 729-781.

Cooke-Davies, T., Cicmil, S.J.K., Crawford, L.H., Richardson, K., 2007. We're not in Kansas anymore, Toto: mapping the strange landscape of complexity theory and its relationship to project management. Proj. Manag. J. 38 (2), $50-61$

Daniel, P.A., Daniel, C., 2018. Complexity, uncertainty and mental models: from a paradigm of regulation to a paradigm of emergence in project management. Int. J. Proj. Manag. 36 (1), 184-197.

Davis, K., 2016. A method to measure success dimensions relating to individual stakeholder groups. Int. J. Proj. Manag. 34 (3), 480-493.

Eriksson, P.E., Larsson, J., Pesämaa, O., 2017. Managing complex projects in the infrastructure sector-a structural equation model for flexibility-focused project management. Int. J. Proj. Manag. 35 (8), 1512-1523.

Geraldi, J., Maylor, H., Williams, T., 2011. Now, let's make it really complex (complicated) a systematic review of the complexities of projects. Int J. Oper. Prod. Manag. 31 (9), 966-990.
Hair, J.F., Black, W.C., Babin, B.J., Anderson, R.E., Tatham, R.L., 2006. Multivariate data analysis. $6^{\text {th }}$ edition. Pearson Prentice Hall, Upper Saddle River, NJ.

Harman, H.H., 1967. Modern Factor Analysis. University of Chicago Press, Chicago, Illinois.

Hensley, R.L., 1999. A review of operations management studies using scale development techniques. J. Oper. Manag. 17 (3), 343-358.

Heravi, G., Gholami, A., 2018. The Influence of Project Risk Management Maturity and Organizational Learning on the Success of Power Plant Construction Projects. Proj. Manag. J. 49 (5), 22-37.

Honour, E.C., 2004. Understanding the Value of Systems Engineering. INCOSE Int. Symp. 14 (1), 1207-1222.

Hu, L., Bentler, P.M., 1999. Cutoff criteria for fit indexes in covariance structure analysis: conventional criteria versus new alternatives. Struct. Equ. Model. 6 (1), 1-55.

Hu, A.H., Hsu, C.W., Kuo, T.C., Wu, W.C., 2009. Risk evaluation of green components to hazardous substance using FMEA and FAHP. Expert Syst. Appl. 36 (3), 7142-7147.

Kahneman, D., 2011. Thinking, Fast and Slow. Farrar Straus Giraux, New York, USA.

Karlsson, C., Ahlstrom, P., 1996. Assessing changes Towards Lean production. Int. J. Oper. Prod. Manag. 16 (2), 24-41.

Kennedy, M., 2008. Ready, Set, Dominate. Oaklea Press, Virginia.

Krippendorff, K., 2013. Content Analysis. An Introduction to its Methodology. 3rd Edition. Sage Publications, Inc, Los Angeles.

Krishnan, V., Ulrich, K.T., 2001. Product Development decisions: a Review of the Literature. Manag. Sci. 47 (1), 1-21.

Lawson, M.B., 2001. In praise of slack: Time is of the essence. Acad. Manag. Exec. 15 (3), 125-135

Liker, J.K., 2004. The Toyota Way. Management Principles from the World"s Greatest Manufacturer. McGraw-Hill, New York, U.S., p. 14.

Liker, J.K., Morgan, J., 2011. Lean Product Development as a System: a Case Study of Body and Stamping Development at Ford. Eng. Manag. J. 23 (1), $16-28$.

Liker, J.K., Sobek II, D.K., Ward, A.C., Cristiano, J.J., 1996. Involving suppliers in Product Development in the United States and Japan: evidence for Setbased concurrent Engineering. IEEE Trans. Eng. Manag. 43 (2), 165-178.

Locatelli, G., Mancini, M., Romano, E., 2014. Systems Engineering to improve the governance in complex project environments. Int. J. Proj. Manag. 32 (8), $1395-1410$

Locher, A., 2008. Value Stream Mapping for Lean Development: A How-to Guide for Streamlining Time to Market. CRC Press, New York.

Lu, Y., Luo, L., Wang, H., Le, Y., Shi, Q., 2015. Measurement model of project complexity for large-scale projects from task and organization perspective. Int. J. Proj. Manag. 33 (3), 610-622.

Metcalfe, M., Sastrowardoyo, S., 2013. Complex project conceptualisation and argument mapping. Int. J. Proj. Manag. 31 (8), 1129-1138.

Morgan, J.M., Liker, J.K., 2006. The Toyota Product Development System: Integrating People, Process, and Technology. Productivity Press, New York, NY.

Murman, E.M., Allen, T., Bozdogan, K., Cutcher-Gershenfeld, J., McManus, H., Nightingale, D., Rebentisch, E., Shields, T., Stahl, F., Walton, M., Warmkessel, J., Weiss, S., Widnall, S., 2002. Lean enterprise value: Insights from MIT's Lean Aerospace Initiative. Palgrave, Hampshire, U.K. 
Nunnally, J.C., 1978. Psychometric Theory. 2nd ed. McGraw-Hill, New York.

Oehmen, J., 2012. The Guide to Lean Enablers for Managing Engineering Programs. Massachusetts Institute of Technology, International Council for Systems Engineering and Project Management Institute, U.S.A.

Oehmen, J., Rebentisch, E., 2010. Waste in Lean Product Development. Massachusetts Institute of Technology (Working Paper. July).

Ohno, T., 1988. Toyota Production System: Beyond Large-Scale Production. Productivity Press, New York.

Oppenheim, B.W., 2004. Lean product development flow. Syst. Eng. 7 (4), 352-376.

Oppenheim, B.W., Murman, E.M., Secor, D.A., 2011. Lean Enablers for Systems Engineering. Syst. Eng. 14 (1), 29-55.

Padalkar, M., Gopinath, S., 2016. Are complexity and uncertainty distinct concepts in project management? A taxonomical examination from literature. Int. J. Proj. Manag. 34 (4), 688-700.

Papke-Shields, K.E., Boyer-Wright, K.M., 2017. Strategic planning characteristics applied to project management. Int. J. Proj. Manag. 35 (2), 169-179.

Pfeifer, J., Barker, K., Ramirez-Marquez, J.E., Morshedlou, N., 2015. Quantifying the risk of project delays with a genetic algorithm. Int. J. Prod. Econ. 170, 34-44.

Podsakoff, P.M., MacKenzie, S.B., Jeong-Yeon, L., Podsakoff, N.P., 2003. Common Method Biases in Behavioral Research: a critical Review of the Literature and Recommended Remedies. J. Appl. Psychol. 88 (5), 879.

Popaitoon, S., Siengthai, S., 2014. The moderating effect of human resource management practices on the relationship between knowledge absorptive capacity and project performance in project-oriented companies. Int. J. Proj. Manag. 32 (6), 908-920.

Reinertsen, D., 2005. Let it flow: how lean product development sparked a revolution. Ind. Eng. 37 (6), 40-45.

Rezvani, A., Chang, A., Wiewiora, A., Ashkanasy, N.M., Jordan, P.J., Zolin, R., 2016. Manager emotional intelligence and project success: the mediating role of job satisfaction and trust. Int. J. Proj. Manag. 34 (7), 1112-1122.

Rossi, M., Terzi, S., 2017. CLIMB: maturity assessment model for design and engineering processes. Int. J. Product Lifecycle Manag. 10 (1). https://doi. org/10.1504/IJPLM.2017.082998.

Rossi, M., Kerga, E.T., Taisch, M., Terzi, S., 2011. Proposal of a Method to Systematically Identify Wastes in New Product Development Process. Concurrent Enterprising (ICE), 17th International Conference on Concurrent Enterprising Proceedings.

Rossi, M., Morgan, J., Shook, J., 2017. Lean Product Development. In: Netland, T.H., Powell, D. (Eds.), The Routledge Companion to Lean Management. Routledge, New York.
Segismundo, A., Augusto Cauchick Miguel, P., 2008. Failure mode and effects analysis (FMEA) in the context of risk management in new product development: a case study in an automotive company. Int. J. Quality Reliab. Manag. 25 (9), 899-912.

Serrador, P., Turner, R., 2015. The relationship between project success and project efficiency. Proj. Manag. J. 46 (1), 30-39.

Serrador, P., Turner, R., 2015b. What is enough planning? Results from a global quantitative study. IEEE Trans. Eng. Manag. 62 (4), 462-474.

Smith, J.L., 1998. Concurrent Engineering in the Jet Propulsion Laboratory: Project Design Centre. pp. 98-AMTC-83.

Sobek II, D.K., Liker, J., Ward, A.C., 1998. Another look at how Toyota Integrates Product Development. Harv. Bus. Rev. 76 (4), 36-47.

Sobek II, D.K., Ward, A.C., Liker, J.K., 1999a. Toyota's principles of set-based concurrent engineering. Sloan Manag. Rev. 40 (2), 67-83.

Sobek II, D.K., Ward, A.C., Liker, J.K., 1999b. Toyota's principles of setbased concurrent engineering. Sloan Manag. Rev. 40 (2), 67-83.

Stamatis, D.H., 2003. Failure Mode and Effect Analysis: FMEA from Theory to Execution. ASQ Quality Press.

Stevens, J., 1986. Applied Multivariate Statistics for the Social Sciences. Lawrence Erlbaum Associates, Hillsdale, NJ, USA.

Turner, R., Zolin, R., 2012. Forecasting success on large projects: developing reliable scales to predict multiple perspectives by multiple stakeholders over multiple time frames. Proj. Manag. J. 43 (5), 87-99.

Van de Vonder, S., Demeulemeester, E., Herroelen, W., Leus, R., 2005. The use of buffers in project management: the trade-off between stability and makespan. Int. J. Prod. Econ. 97 (2), 227-240.

Vidal, L.A., Marle, F., Bocquet, J.C., 2011. Measuring project complexity using the Analytic Hierarchy Process. Int. J. Proj. Manag. 29 (6), 718-727.

Ward, A.C., Sobek, D.K., 2014. Lean Product and Process Development. Lean Enterprise Institute, Cambridge, MA, USA.

Whitty, S.J., Maylor, H., 2009. And then came complex project management (revised). Int. J. Proj. Manag. 27 (3), 304-310.

Williams, T.M., 1999. The need for new paradigms for complex projects. Int. J. Proj. Manag. 17 (5), 269-273.

Womack, J.P., Jones, D.T., 1996. Lean Thinking: Banish Waste and Create Wealth in your Corporation. Simon \& Schuster, New York.

Womack, J.P., Jones, D.T., Roos, D., 1990. The Machine that Changed the World. Rawson Associates, New York.

Yin, R.K., 2003. Applications of Case Study Research - Second Edition. Sage publications, U.S.A. 